RESEARCH ARTICLE

\title{
Use of Organic acid coated phosphatic fertilizer to improve growth and phosphorus use efficiency of brinjal
}

\author{
Anju Mohan ${ }^{1}$ and Malarvizhi $\mathbf{P}^{1 *}$ \\ ${ }^{* 1}$ Department of Soil Science and Agricultural Chemistry, Tamil Nadu Agricultural University, Coimbatore - 641003
}

Received : $08^{\text {th }}$ July, 2020

Revised : $11^{\text {th }}$ August, 2020

Revised : $18^{\text {th }}$ August, 2020

\begin{abstract}
Phosphorus nutrition plays a significant role in the growth and yield of crops, but it is the most deficient nutrient in the soil. Coating of the phosphorus $(P)$ fertilizers can control the release of nutrients and improve the efficiency. In this study organic acids such as humic acid and fulvic acid are used as the coating material for gradual release of $\mathrm{P}$ from the Di ammonium phosphate (DAP) fertilizer. In the present investigation Brinjal (Var. C02) was used as the test crop. The study emphasizes enhanced phosphorus use efficiency (PUE) along with improved growth of brinjal at different rates of organic acids (Humic acid and Fulvic acid) coated DAP in comparison with uncoated DAP. In the incubation experiment the release pattern of $\mathrm{P}$ in soil from different coating concentrations $(0,5,10,15,20 \%)$ was tested under controlled condition and the growth and PUE were tested under field conditions. Results showed that at 60 days of incubation T9 (20\% HA coated DAP) showed maximum $P$ release and the application of $\mathrm{NK}+\mathrm{P}$ as HA coated DAP (20\%) increased plant height, number of leaves, leaf area, dry matter production and PUE in brinjal. These results proved that organic acid coated DAP could be used as an effective fertilizer to improve growth and PUE in brinjal over uncoated DAP
\end{abstract}

Keywords: Humic acid; Fulvic acid; Incubation study; Growth; PUE

\section{INTRODUCTION}

Vegetables constitute a significant part of human diet supplying the essential nutreints, vitamins and other vital substances required for a healthy life. Brinjal (Solanum melongena L.) is one of the most important vegetable crops having nutritional value with respect to vitamins $A, C$ and minerals.

Fertilizers are the nutrient source which will provide sufficient nutrients for the plant growth. Fertilizers are essential for commercial farming and tremendous yields. Phosphorus is the main element required for the plant's growth. $P$ is essential for root growth; act as an energy source also. Phosphorus however commonly limits plant growth in deficient condition. The major problem in $\mathrm{P}$ uptake from soil by root is the very low solubility of most of the phosphorus compounds resulting in a low concentration of phosphate ions in the soil solution

The PUE is very low in alkaline soil due to fixation with calcium or magnesium ions which reduces the $P$ availability to the plants. Coating of phosphorus fertilizers with organic acids can improve the PUE without harming the environment.

Humic acids (HA) and Fulvic acids (FA) are natural biostimulants which will improve the growth of plants.
The coating of fertilizers using organic acids will help in improving the fertilizer efficiency and also it will reduce the fertilizer losses. Paramasivam et al., (2015) studied the influence of humic acid on growth and yield of brinjal. Application of $75 \% R D F+10 \mathrm{~kg}$ $\mathrm{HA}+0.2 \% \mathrm{HA}$ recorded significantly higher plant height, number of branches/plant, fruit yield and total dry matter production compared to control. El-Nemr et.al (2015) showed that all morphological parameters of egg plants were improved by application of biostimulators. Humic acids acts as a soil conditioner and enhance the ability of soil to hold more nutrients which are available to plant (lqbal and Mastorakis, 2014). Adani et.al (1998) reported that humic acid believed to increase nitrogen use efficiency and stimulated shoot and root length. Suh et al., (2014) studied the effects of foliar application of Fulvic acid on plant growth, fruit quality and yield of tomato. Different levels of Fulvic acid sprayed on plants and these treatments led to a significant increase in plant height, fresh and dry weight.

DAP is the most widespread phosphate fertilizer because of its high analysis and good physical properties. Phosphorus however commonly limits plant growth in deficient condition. The main reason for this deficiency is rapid dissolution and fixation of nutrients in the soil. For reducing $P$ losses and 
to improve PUE, gradual release of $P$ is essential. Gradual release can be promoted by coating $P$ fertilizer . Pauly et al., (2002), assessed coated fertilizers by using various coatings to regulate release of $\mathrm{P}$ and to compare the growth and $\mathrm{P}$ uptake of barley in greenhouse. Net fertilizer P efficiency, dry matter production, $P$ uptake, and net fertilizer release efficiency were better in coated fertilizers.

Keeping the above points the present study was undertaken to standardize organic acid coating (humic acid, fulvic acid) for phosphatic fertilizer to improve growth as well as PUE in Brinjal.

\section{MATERIAL AND METHODS}

\section{Experimental material for laboratory studies}

An incubation study was conducted to observe the $P$ release from the HA and FA coated DAP. The experiment was conducted at Department of Soil Science and Agricultural Chemistry, Tamil Nadu Agricultural University, Coimbatore.

The coatings of phosphate fertilizers DAP (granular), using humic acid and fulvic acid with the coating percentage of $0,5,10,15$, and 20 were carried out. The coating was done using oil (vegetable oil). Initially then with humic acid and Fulvic acid separately by physical mixing. Then the fertilizer was dried in hot water bath until the moisture was removed completely. The dried material was used for the experiment.

The soil was collected from the location of field experiment. The texture of the soil was sandy loam. The soil was low in available $\mathrm{N}$, high in available $\mathrm{P}$, and high in available $\mathrm{K}$ with $\mathrm{EC} 0.29 \mathrm{dS} \mathrm{m}^{-1}$ and $\mathrm{pH}$ 8.45. Disposable cups of $250 \mathrm{~cm}^{3}$ were used and each cup was filled with $100 \mathrm{~g}$ soil. Saturation percentage of soil used was determined to maintain moisture content in cups. Coated and uncoated DAP were applied in cups with respective concentration according to the treatment schedule, and mixed with soil thoroughly. The incubation study lasted for 60 days and the samples were taken for analysis at $0.7,15,30,45, \& 60$ days.

The available soil $\mathrm{P}$ was estimated using $0.5 \mathrm{M}$ $\mathrm{NaHCO}_{3}$ at $\mathrm{pH} 8.5$ as per the standard procedure ( Olsen et.al,1954).

Field experiment: Field experiment was conducted during winter season (October November) at a Farmer's field at Thondamuthur block of Coimbatore district .The experimental site is geographically located at $10^{\circ} 59^{\prime} \mathrm{N}$ latitude and $76^{\circ} 49^{\prime}$ E longitude at an altitude of $315 \mathrm{~m}$ above MSL. Coimbatore recorded excess rainfall in 2019. In the four rainfall seasons, Coimbatore received $859.50 \mathrm{~mm}$ rainfall which is $27.5 \%$ more than 50 year's average rainfall. An amount of $450 \mathrm{~mm}$ of rain was received during North east monsoon season. The mean maximum and minimum temperatures were $32.5^{\circ} \mathrm{C}$ and $21^{\circ} \mathrm{C}$, respectively. The field experiment was laid out in Randomized Block Design (RBD) and consisted of ten treatments and replicated thrice. The treatments comprised of $\mathrm{T} 1$ : $\mathrm{NK}+\mathrm{P}$ as uncoated DAP, T2:NK + P as FA coated DAP(5\%), T3: NK + P as FA coated DAP (10\%), T4: $\mathrm{NK}+\mathrm{P}$ as FA coated DAP (15\%), T5: NK + P as FA coated DAP (20\%), T6 NK + P as HA coated DAP (5\%), T7 : NK+ P as HA coated DAP (10\%), T8 : NK + P as HA coated DAP (15\%), T9 : NK + P as HA coated DAP (20\%), T10 : control . Urea and MOP were used as the $\mathrm{N}$ and $\mathrm{K}$ sources respectively. The coating of fertilizers was done as done for incubation study.

The main field was ploughed and ridges and furrows were formed at a spacing of $60 \mathrm{~cm}$. The Brinjal (CO2) seedlings were raised in the nursery for transplanting. Transplanting of 25-30 days old seedling was carried out at $60 \mathrm{~cm}$ apart on the ridges. Recommended cultural practices such as weeding, irrigation and plant protection were preformed. Nitrogen and Potassium was applied in the form of Urea and MOP as per the fertilization schedule for Brinjal. Phosphorous was applied in the form of HA\&FA coated DAP. Recommended dose of brinjal (As per STCR recommendation) is 127:37:100 kg N: $\mathrm{P}_{2} \mathrm{O}_{5}: \mathrm{K}_{2} \mathrm{O}$ ha $^{-1}$. The fertilizer was applied as per the fertilization schedule of Brinjal variety at different growth stages. Tewnty five days older brinjal seedlings were transplanted in the field and the observations were taken at 30 days interval. The growth and yield parameters were recorded. The cultural operations were carried out based on CPG (2012).

Five plants in each plot other than guard row were randomly selected and tagged for recording observations on growth and yield parameters. The plant height was recorded in centimeters. Leaf area is measured by using length and breadth of leaves. Five plants were taken from sampling rows for recording the dry matter production at active 30 and 60 days after transplanting and also during the harvest stage. The plant samples were collected with utmost care not to damage the roots. The samples were cleaned, separated, shade dried and then oven dried at $70 \pm \pm 5^{\circ} \mathrm{C}$ until a constant weight is obtained and dry weight was recorded in $\mathrm{kg}$.

Soil available $\mathrm{P}$ at each stage was analyzed for available $P$ by using Olsen's extractant. Total phosphorus was determined by taking a known quantity of tri acid extract of the plant and $P$ was determined using wavelength at $470 \mathrm{~nm}$ of Spectrophotometer (Jackson,1973). PUE is related to the P sources, environmental factors, and soil and crop management. It is define as the yield increase per kilogram due to fertilizer $\mathrm{P}$ added. 


\section{Statistical analysis}

$$
\text { PUE (kg kg-1) }
$$

The data on the various characters recorded were statistically analysed under randomized block design as suggested by Gomez and Gomez (1984). In laboratory analysis data recorded were statistically analysed under Completely randomized design. Wherever the treatment differences were found to be significant ( $F$ test), critical differences were worked out at five per cent probability level $(P=0.05)$ and the treatment differences that were found not to be significant was denoted NS (Nonsignificant) in the respective tables.

\section{RESULTS AND DISCUSSION}

Results pertaining to the incubation experiment of growth and phosphorus use efficiency of brinjal in a field experiment is given below

Table 1. Effect of HA\&FA coated phosphatic fertilizer on available P status ( $\left.\mathrm{kg} \mathrm{ha}^{-1}\right)$ - Incubation study.

\begin{tabular}{clrrrrrr}
\hline Tr.No & Treatments & \multicolumn{5}{c}{ Days after incubation } \\
\cline { 3 - 8 } & & $\mathbf{0}^{\text {th }}$ day & $7^{\text {th }}$ day & $\mathbf{1 5}^{\text {th }}$ day & $3^{\text {th }}$ day & $4^{\text {th }}$ day & $60^{\text {th }}$ day \\
\hline $\mathrm{T}_{1}$ & NK+ P as Uncoated DAP & 36.12 & 39.48 & 47.80 & 41.78 & 37.89 & 32.90 \\
$\mathrm{~T}_{2}$ & NK+ P as FA coated DAP (5\%) & 32.69 & 35.85 & 44.12 & 49.21 & 46.12 & 42.98 \\
T3 & NK+ P as FA coated DAP (10\%) & 30.12 & 34.21 & 43.12 & 47.21 & 49.26 & 50.75 \\
T4 & NK+ P as FA coated DAP (15\%) & 28.28 & 33.26 & 44.12 & 49.02 & 51.07 & 53.49 \\
T5 & NK+ P as FA coated DAP (20\%) & 27.11 & 31.28 & 37.25 & 40.20 & 46.85 & 54.16 \\
T6 & NK+ P as HA coated DAP (5\%) & 32.16 & 36.85 & 44.22 & 49.22 & 47.22 & 44.86 \\
T7 & NK+ P as HA coated DAP (10\%) & 31.22 & 35.90 & 40.26 & 47.22 & 50.78 & 52.21 \\
T8 & NK+ P as HA coated DAP (15\%) & 29.62 & 34.74 & 41.02 & 45.22 & 51.19 & 55.85 \\
T9 & NK+ P as HA coated DAP (20\%) & 27.98 & 33.21 & 42.66 & 47.56 & 52.12 & 57.96 \\
T10 & Control & 29.10 & 30.60 & 31.40 & 27.10 & 26.50 & 25.80 \\
& Mean & 30.44 & 34.54 & 41.59 & 44.37 & 45.90 & 47.09 \\
& SEd & 0.44 & 0.42 & 0.77 & 1.41 & 0.80 & 0.72 \\
& CD(P=0.05) & 0.88 & 0.86 & 1.57 & 2.85 & 1.62 & 1.46 \\
\hline
\end{tabular}

\section{Incubation study}

Significant difference in Olsen's P concentration in soil treated with coated and uncoated DAP fertilizer sources at different time intervals are shown in table 1.Soils treated with the uncoated DAP showed the highest concentration of Olsen's $P$ in the soil after 15 days of incubation period as compared to DAP coated with different concentrations of humic acid and fulvic acid. At 30 days of incubation period a maximum $P$ release was recorded in $5 \%$ HA coated
DAP. Decreasing trend in P release was observed in treatment with uncoated DAP. DAP coated with $5 \%$ HA\&FA showed maximum $P$ release in 30 days of incubation then showed the decreasing trend. The organic acid coated DAP shows an increasing trend in $P$ release up to 60 days of incubation period. At 60 days of incubation T9 (20\% HA coated DAP) recorded maximum $P$ release. Among the treatments, at 60 days, uncoated DAP showed the minimum $P$ release. Similar results were reported by Noor et.al(2017).

Table 2. Response of organic acid-coated DAP fertilizer on growth parameters of brinjal

\begin{tabular}{|c|c|c|c|c|c|}
\hline Tr.No. & Treatments & $\begin{array}{l}\text { Plant height } \\
(\mathrm{cm})\end{array}$ & $\begin{array}{c}\text { Number of } \\
\text { leaves/plant }\end{array}$ & Leaf area $\left(\mathrm{cm}^{2}\right)$ & $\begin{array}{c}\text { Drymatter production } \\
\left(\mathrm{kg} \mathrm{ha}^{-1}\right)\end{array}$ \\
\hline $\mathrm{T}_{1}$ & $\mathrm{NK}+\mathrm{P}$ as Uncoated DAP & 69.20 & 74.50 & 75.20 & 1699 \\
\hline $\mathrm{T}_{2}$ & $\mathrm{NK}+\mathrm{P}$ as FA coated DAP (5\%) & 72.35 & 78.35 & 81.52 & 1786 \\
\hline T3 & $\mathrm{NK}+\mathrm{P}$ as FA coated DAP (10\%) & 78.26 & 81.23 & 87.44 & 2266 \\
\hline $\mathrm{T} 4$ & $\mathrm{NK}+\mathrm{P}$ as FA coated DAP (15\%) & 84.32 & 84.34 & 95.52 & 2375 \\
\hline T5 & $\mathrm{NK}+\mathrm{P}$ as FA coated DAP (20\%) & 86.80 & 86.85 & 96.75 & 2708 \\
\hline T6 & $\mathrm{NK}+\mathrm{P}$ as HA coated DAP (5\%) & 72.35 & 73.26 & 86.90 & 2325 \\
\hline T7 & $\mathrm{NK}+\mathrm{P}$ as HA coated DAP (10\%) & 79.20 & 81.50 & 98.59 & 2413 \\
\hline T8 & $\mathrm{NK}+\mathrm{P}$ as HA coated DAP (15\%) & 85.45 & 88.63 & 102.31 & 2692 \\
\hline T9 & $\mathrm{NK}+\mathrm{P}$ as HA coated DAP (20\%) & 91.20 & 92.87 & 113.05 & 3019 \\
\hline \multirow[t]{4}{*}{ T10 } & Control & 65.64 & 53.65 & 55.47 & 1204 \\
\hline & Mean & 78.48 & 79.52 & 89.27 & 2249 \\
\hline & SEd & 1.46 & 1.38 & 1.55 & 47.98 \\
\hline & $\mathrm{CD}(\mathrm{P}=0.05)$ & 3.08 & 2.91 & 3.25 & 100.80 \\
\hline
\end{tabular}




\section{Field experiment}

The growth parameters obtained from the field experiment are given in table 2

\section{Plant height}

Organic acid coated DAP showed significant effect on plant height. At harvest stage maximum plant height showed by T9 $(20 \% \mathrm{HA}$ coated DAP) which recorded $91.2 \mathrm{~cm}$, followed by T5 (20\%FA coated DAP) with a plant height of $86.80 \mathrm{~cm}$. The shortest plant were recorded in absolute control. The results revealed that organic acid coated DAP application had brought variation in plant height (Fig 1) Similar results were found by El-Nemr et.al (2015), Paramasivan (2015), Azarpour et.al (2012) and Fathima et.al (2013)

Table 3. Response of Organic acid coated DAP fertilizer on PUE and of brinjal (Solanum melongena $\mathrm{L}$.)

\begin{tabular}{clr}
\hline Tr. No. & Treatmen ts & Agronomic PUE $\left(\mathbf{q} \mathbf{~ k g}^{-1}\right)$ \\
\hline$T_{1}$ & NK+ P as Uncoated DAP & 24.92 \\
$T_{2}$ & NK+ P as FA coated DAP (5\%) & 28.19 \\
$T_{3}$ & NK+ P as FA coated DAP (10\%) & 27.57 \\
$T_{4}$ & NK+ P as FA coated DAP (15\%) & 29.23 \\
$T_{5}$ & NK+ P as FA coated DAP (20\%) & 31.73 \\
$T_{6}$ & NK+ P as HA coated DAP (5\%) & 23.69 \\
$T_{7}$ & NK+ P as HA coated DAP (10\%) & 31.27 \\
$T_{8}$ & NK+ P as HA coated DAP (15\%) & 33.82 \\
$T_{9}$ & NK+ P as HA coated DAP (20\%) & 35.84 \\
$T_{10}$ & Control & - \\
\hline
\end{tabular}

\section{Number of leaves per plant}

According to data observed maximum number of leaves were observed in T9 (20\%HA coated DAP) followed by $\mathrm{T} 8$ (15\%HA coated DAP) and the least leaf count was in control. The results showed that organic acid coated phosphatic fertilizer application could improve the number of leaves in plant(Figure 1).

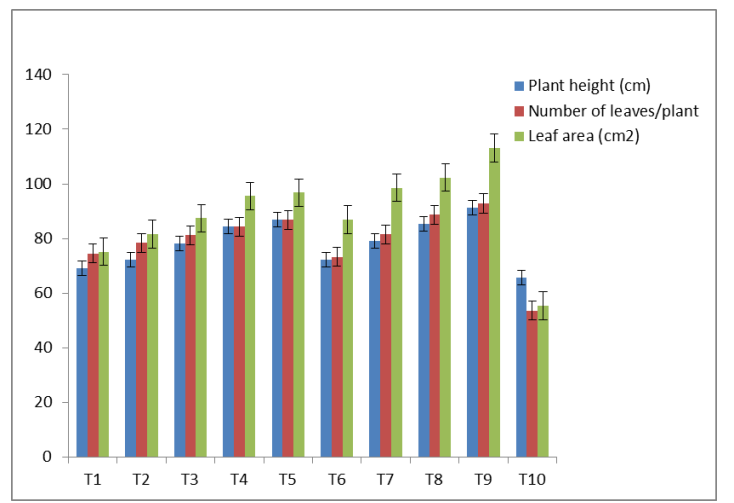

Figure 1. Response of organic acid-coated DAP fertilizer on plant height, number of leaves/plant and leaf area of brinjal

Similar results are reported by Padem et.al (1999) who observed that the addition of humic acid fertilizer improved the number of leaves in egg plant.

\section{Leaf area}

Leaf area was also significantly influenced by the application organic acid coated phosphate fertilizer. The maximum leaf area $\left(113.05 \mathrm{~cm}^{2)}\right.$ was obtained from the treatment T9 (20\%HA coated DAP) followed by T8 ( $15 \%$ HA coated DAP) which received 102.31 $\mathrm{cm}^{2}$. The lowest value $\left(55.47 \mathrm{~cm}^{2}\right)$ was observed from the control (Figure 1). Similar results were observed by Ruban et.al (2019).

\section{Dry matter production (kg ha-1)}

Considering all treatments highest dry matter production (3019.2 $\mathrm{kg} \mathrm{ha}^{-1}$ ) was observed in T9 (20\% HA coated DAP) and the least observed in control. All treatments applied with organic acid coated DAP showed high dry matter production compared to control(Figure 2).

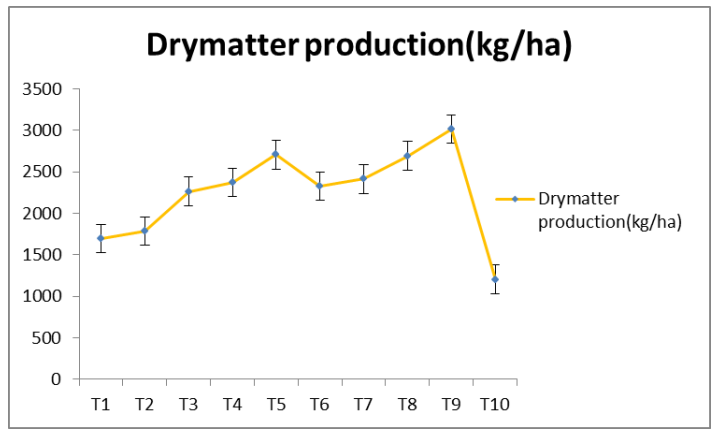

Figure 2. Response of organic acid-coated DAP fertilizer on dry matter production of brinjal

Similar results were found by Chtouki et al (2020), Abdel-Razzak et al (2012) and Paramasivan (2015) in brinjal.

\section{Phosphorus use efficiency (PUE)}

Effects of organic acid coated DAP on phosphorus use efficiencies are reflected from the Table 3. Results showed that Agronomic efficiency (AE) is 
increasing with increase in the coating percentage of organic acid. Highest PUE is observed in $20 \%$ HA coated DAP (T9) which is $43.8 \%$ higher than uncoated DAP application (Figure 3). Similar results were observed by Chtouki et al (2020) in calcareous soil and Noor et al (2017).

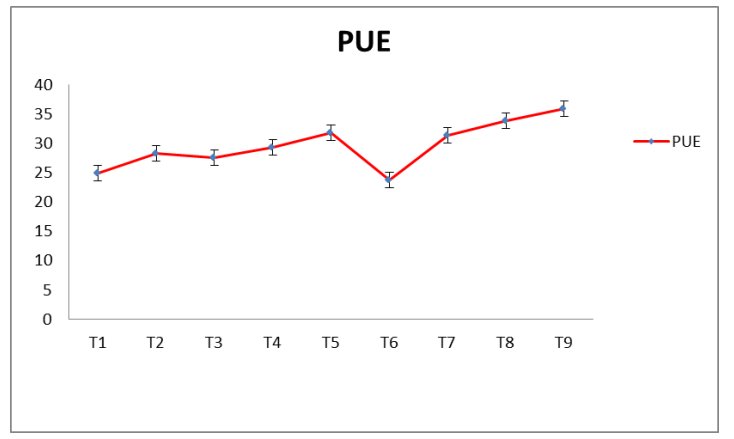

Figure 3. Response of organic acid-coated DAP fertilizer on PUE of brinjal.

All treatments received 127:37:100 kg N: $\mathrm{P}_{2} \mathrm{O}_{5}: \mathrm{K}_{2} \mathrm{O}$ $\mathrm{ha}^{-1}$ as per soil test based recommendation. $\mathrm{N}$ as Urea, $\mathrm{P}$ as Coated DAP and $\mathrm{K}$ as MOP.

\section{CONCLUSION}

The organic acid-coated phosphate fertilizers are superior over uncoated DAP in achieving phosphorus release, growth and agronomic phosphorus use efficiency in brinjal. Among the organic acid-coated treatments, 20\% HA coated DAP showed the best results in vegetative production and phosphorus use efficiency. In incubation study also organic acid coated phosphatic fertilizer showed higher $P$ release than uncoated DAP. Hence, the present study revealed that organic acid-coated phosphate fertilizer can be safely used within the applied concentrations with a positive effect on growth, $P$ release and PUE.

\section{REFERENCES}

Abdel-Razzak, H.S. and G.A. El-Sharkawy. 2012. Effect of Biofertilizer and Humic Acid Applications on Growth, Yield, Quality and Storability of Two Garlic(Allium sativum L.) Cultivars. Asian Journal of Crop Science, 5(1): 48-64.

Adani, F., Genevini, P., Zaccheo, P. and G.Zocchi. 1998. The effect of commercial humic acid on tomato plant growth and mineral nutrition. Journal of plant nutrition, 21(3): 561-575.

Azarpour, E., Motamed, M.K., Moraditochaee, M. and H.R. Bozorgi. 2012. Effects of bio, mineral nitrogen fertilizer management, under humic acid foliar spraying on fruit yield and several traits of eggplant (Solanum melongena L.). African Journal of Agricultural Research, 7(7): 1104-1109.
Chtouki, M., Lyamlouli, K., Oukarroum, A. and Y. Zeroual. 2020. Humic acid coated $P$ fertilizers to improve phosphorus use efficiency in calcareous soils.

El-Nemr, M.A., El-Bassiony, A.M., Tantawy, A.S. and Z.F.Fawzy. 2015. Responses of eggplant (Solanum melongena var. esculenta L) plants to different foliar concentrations of some Bio-Stimulators. Middle East J. Agric. Res, 4(4): 860-866.

Fathima, P.S. and G.R.Denesh. 2013. Influence of humic acid spray on growth and yield of chilli (Capsicum annum L.). International Journal of Agricultural Sciences, 9(2): 542-546

Gomez, K.A. and A.A.Gomez. 1984. Statistical procedures for agricultural research. John Wiley \& Sons.

IQBAL, S. and N. MASTORAKIS. 2014. Effect of Various Growth Mediums on the Germination and Growth of Jatropha curcas. In Proceedings of the 2nd International Conference of Geodesy \& Geomatics Engineering.(GENG'14), Brasov, Romania (Vol. 26, No. 28: 147-156).

Jackson, M. L. 1973. Soil chemical analysis Prentice Hall of India Pvt Ltd., New Delhi

Noor, S., Yaseen, M., Naveed, M. and R.Ahmad. 2017. Use of controlled release phosphatic fertilizer to improve growth, yield and phosphorus use efficiency of wheat crop. Pak. J. Agri. Sci, 54(4): 541-547

Olsen, S.R. 1954. Estimation of available phosphorus in soils by extraction with sodium bicarbonate (No. 939). US Department of Agriculture.

Pauly, D.G., Malhi, S.S. and M. Nyborg. 2002. Controlled-release $\mathrm{P}$ fertilizer concept evaluation using growth and $\mathrm{P}$ uptake of barley from three soils in greenhouse.Canadian journal of soil science, 82(2): 201-210.

Padem, H., Ocal, A. and R. Alan. 1999. Effect Of Humıc Acıd Added To Folıar Fertılızer On Qualıty And Nutrient Content Of Eggplant And Pepper Seedlıngs. Acta Hort.(ISHS), 491: 241-246.

Paramasivan, M. 2015. Studies on influence of humic acid on growth and yield of brinjal var. KKM1 in Alfisols of Tamil Nadu. Indian Journal of Horticulture, 72(3): 438-440.

Ruban, S., Priya, M.R., Barathan, G. and S.S.Kumar.2019. EFFECT OF FOLIAR APPLICATION OF BIOSTIMULANTS ON GROWTH AND YIELD OF BRINJAL (Solanum melongena L.). Plant Archives, 19(2): 2126-2128.

Suh, H.Y., Yoo, K.S. and S.G. Suh 2014. Effect of foliar application of fulvic acid on plant growth and fruit quality of tomato (Lycopersicon esculentum L.). Horticulture, Environment, and Biotechnology, 55(6): 455-46 